in a variety of subjects, and courses for the training of laboratory assistants and stewards; also that industry should provide special training, and apprenticeship schemes for juniors might prove of great advantage.

\section{FLAGELLAR MOVEMENTS}

$\mathrm{T}$ HE mechanics of flagellar movements and the swimming of aquatic micro-organisms form a subject of great complexity, towards an understanding of which A. G. Lowndes (Proc. Zool. Soc., 114 (111), 325; 1944) makes a critical contribution in respect of Monas stigmatica Pringsheim, Peranema tricophorum (Ehrbg.) Stein. and Volvox sp., and at the same time effectively refutes several statements about this process that have made their appearance in standard text-books of biology.

$M$. stigmatica is exceptionally sensitive to light, and although it swims actively and rapidly in subdued daylight, exposure to the light of an ordinary electric bulb induces a cessation of normal swimming. This, coupled with its high rate of movement, makes observation on, and photography of, flagellar movements and swimming difficult or impossible. Direct observation showed a maximum rate of swimming of $0.260 \mathrm{~mm}$. per sec., that is, more than forty times its own length per sec.; but observations of flagellar movement at this rate of swimming were not possible. When the rate of swimming is reduced to about one twenty-sixth of normal, the long flagellum (about two and a half times the length of the cell) is held out in front of the organism, and waves which originate at its base pass regularly along it; at the same time a current is set up in the water, and this flows in the opposite direction (that is, tip to base) and past the anterior end of the organism. This is the condition of the long flagellum when the organism is moving slowly, and in the normally slow-moving Peranema the flagellum is also held extended in front of the cell with the anterior end of the flagellum vibrating. Stimulation causes the whole flagellum to beat violently, but this does not bring about an acceleration in the rate of movement of the cell. Instead the organism ceases swimming momentarily, and then changes its direction of movement. Hence statements that Peranema exhibits a slow forward movement during which undulations of the flagellum are confined to its anterior end, and a rapid movement accompanied by undulation along the whole length of the flagellum, appear to be incorrect.

Experiments with a physical model, for example, a leather thong rotated under water, show that it is possible to propel from base to apex (that is, from the attached to the free end) of the thong a series of waves of decreasing amplitude and wave-length. With the thong all the energy is applied at one end, but with a flagellum, while most of the energy may be applied to its base by the attached cell, the flagellum itself generates energy so that no decrease in the amplitude or length of waves passing along it need occur. Increasing the speed of rotation of the thong causes it to swing from side to side, and it may finally twist up, but shortening it increases its stability. When two thongs are attached to the arms of a Y-tube which is itself attached to a spindle and the whole rotated rapidly under water, the thongs bend outwards, and if the spindle moves forward the thongs bend backwards. If, however, the spindle is rotated relatively slowly, a current of water is caused to flow towards the base of the thongs and at this rate of movement the thongs do not bend outwards.

In Monas, when the swimming is slow, the flagellum is extended forward, but if the movement is rapid the long flagellum bends and trails behind the cell and causes the organism to gyrate and rotate. It is probable that in other fast-moving organisms the flagella trail behind and are not extended in front of the cell as they are in slow-swimming types. In Volvox, a slow-moving coenobial alga, the pairs of cilia remain fully extended and each pair draws a current of water towards the surface of the cœenobium, but the precise contribution that these currents make towards the movement of the Volvox colony is not clear.

L. G. G. WARNE.

\section{FOOD IN HOSPITALS}

A $\mathrm{N}$ interesting article in the Lancet (61, Jan 13, A 1945) discusses the monotonous, badly cooked and often scanty menus provided by hospitals. The fault lies, the writer concludes, not only with the hospitals, which fail to appreciate the importance of correct feeding and, in most instances, to employ a single experienced food officer with sufficient influence over the hospital's income, but also with the medical men, who do not insist that their patients' needs are properly met.

The quantity of food in hospitals is often insufficient and it has to be eaten in a hurry, for the nurses have to be getting on with the next job. The medical man could criticize the arrangements on all these grounds, and he should do so, paying special attention to the quality of 'light diet', when it is ordered. The blame has to be distributed between the hospital steward, the matron, the cooks, the out-ofdate kitchen equipment, the methods of preparing, carving and serving the food, its transport along draughty corridors on unheated trolleys with delays, wilful or inevitable, on the way, and so on. The solution of this problem requires, the writer concludes, a more unified control. The prescription of diets is, and must remain, part of the treatment ; the ward sister, who knows her individual patients' likes and dislikes, should interpret the prescriptions; but the buying, cooking and distribution of the food should not be done by three separate officers. Further, adequate meals should be provided throughout the day, inexpert buying and failure to use the open market should be eliminated, sufficient skilled kitchen staff should be provided, and the kitchen should have modern equipment and labour-saving devices.

A second article (Lancet, 94, Jan. 20, 1945) discusses the question: What is good feeding? The hospital should construe scientific knowledge of food values with the caterer's art of producing appetizing meals. Enough food of the right kind should be economically bought, properly stored and wisely cooked. Individual appetites vary, and those of sick people need special consideration. The lack of the important effects of the sights, smells and talk of the dining table can be counteracted by serving the food attractively. A third article (Lancet, 123, Jan. $27,1945)$ suggests remedies for existing faults, with instances of improvements that have been made. The writer's evident understanding of the difficulties of all who are concerned with hospital food, his sympathy with them and with the patients, and his lively style, make these articles as attractive as they are valuable. 